\title{
A Rare Association between Meningioma and Two Intracranial Vascular Lesions: Case Report and Review of Literature
} \author{
Franco Ammannati ${ }^{5}$ \\ ${ }^{1} \mathrm{MD}$, Resident in Neurosurgery, University of Florence, Florence, Italy \\ ${ }^{2} \mathrm{MD}$, Consultant in Neurosurgery, Azienda Ospedaliero Universitaria Careggi, Florence, Italy \\ ${ }^{3} \mathrm{MD}$, Neurosurgery Clinic, University of Florence, Italy \\ ${ }^{4} \mathrm{MD}$, Director of Interventional Neuroradiology, Azienda Ospedaliero Universitaria Careggi, Florence, Italy \\ ${ }^{5} \mathrm{MD}$, Director of Neurosurgical Department, AOUC, Florence, Italy
}

Andrea Boschi ${ }^{1}$, Giovanni Barbagli ${ }^{*}$, Bahman Ashraf-Noubari ${ }^{2}$, Edvardo Cipolleschi ${ }^{3}$, Salvatore Mangiafico ${ }^{4}$,

* Corresponding Author Address: Department of Neurosurgery, University of Florence, Italy, via Dante da Castiglione 33, 50125, Florence, Italy. Fax: +390552299984, Email: barbagli.giovanni@gmail.com

Article Type: Case Report

Received: January 19, 2016, Last Revised: April 27, 2016, Accepted: May 2, 2016

\section{Abstract}

Background \& Importance: Our study was performed based on the first case, reported in English, of a patient with three contemporary lesions, an extra-axial malformation and two vascular ones.

Case Presentation: A 62-year-old man referred to our clinic due to right hand tremor associated to a slowing of idea-forming function and movements. The neuroradiological evidence showed a right fronto-temporal meningioma with the contemporary presence of an arteriovenous malformation (AVM) and of an aneurysm. The neuroradiological finding showed, also, a presumably "flow-related" right carotid-ophthalmic aneurysm with two millimeters in size. We performed the meningioma excision by the usage of cavitron ultrasonic surgical aspirator (CUSA), after the isolation of the sylvian fissure with the microdoppler and the removal of the AVM by the Hashimoto technique. Considering the very small size of the aneurysm, we decided to leave it in site.

Conclusion: The post-operative examination showed a complete removal of the lesions, meningioma and AVM. We performed an exhaustive review of the current literature, and the result encompassed only another case, written in Japanese, about the contemporary presence of these three lesions.

Keywords: Meningioma; Brain Arteriovenous Malformation; Brain Aneurysm; Association; Literature

Please cite this paper as: Boschi A, Barbagli G, Ashraf-Noubari B, Cipolleschi E, Mangiafico S, Ammannati F. A Rare Association between

Meningioma and Two Intracranial Vascular Lesions: Case Report and Review of Literature. Iran. J. Neurosurg. 2016;2(1):22-24

\section{Background and Importance}

Association between cranial meningiomas and intracranial vascular malformations (aneurysms and arteriovenous malformations (AVMs)) is a very rare occurrence. From a Pubmed-MEDLINE review, 50 cases of AVMs associated with primary intracranial tumors have been previously reported. Among these, only 14 cases involved the association between AVMs and meningiomas (1). Coexistence of an aneurysm and a meningioma was shown approximately in 100 cases (2). The association between AVMs and aneurysm according to their similar vascular nature is well known. The case we reported on is the first in English literature since the only other case in the whole literature was published in Japanese.

\section{Case Presentation}

A 62-year-old man was admitted to our hospital presenting with confusion, ideomotor slowing down and right hand tremor accentuated with the efforts. These symptoms appeared about two months before admission, and worsened gradually. In patient's medical history, the presence of chronic obstructive pulmonary disease (COPD) was detected, and arterial hypertension with previous myocardial infarction (MI), diabetes, and the presence of a pulmonary lesion were diagnosed during hospitalization. At neurological examination, the patient was cooperative, slightly confused with Glasgow coma scale (GCS) $=15$. We did not find any evident neurological deficit, except for an ideomotor slowing down. Also, encephalic nerves did not show any evident deficit.

\section{Pre-operative Neuroimanging}

An MRI with gadolinium showed a right massive extra-axial lesion compressing the fronto-temporal parts of cerebrum and the right cerebral peduncle displacing the ventricular system (Figures 1.A-B). In its posterior side, the lesion was in contact with an AVM. The AGF revealed that the AVM's nidus had a diameter of three centimeters with the feeders coming from right middle cerebral artery (MCA) and anterior choroidal artery (AChA) and two large venous drainage areas from the vein of Labbé and the vein of Trolard from the same side (Figures 1.C-D), thus configurating an AVM Spetzler-Martin 2. The angiography had also revealed an aneurysm located near the rise of the ophthalmic artery with a diameter of two millimeters (Figures 1.C-D).

\section{Surgery}

The patient was placed in supine position with his head turned to the left. Afterwards, a point mark skin incision was made and a large fronto-temporal craniotomy was performed. Then, the dura was opened and a large meningioma occupying large part 
of the craniotomy perimeter was found. Total removal of the lesion was performed after isolation of the sylvian artery with the help of microdoppler. Subsequently, we exposed the AVM, by transuncal approach. The AVM was then isolated according to the Hashimoto technique and removed. Due to the very small dimension of the aneurysm, the lesion was not treated.
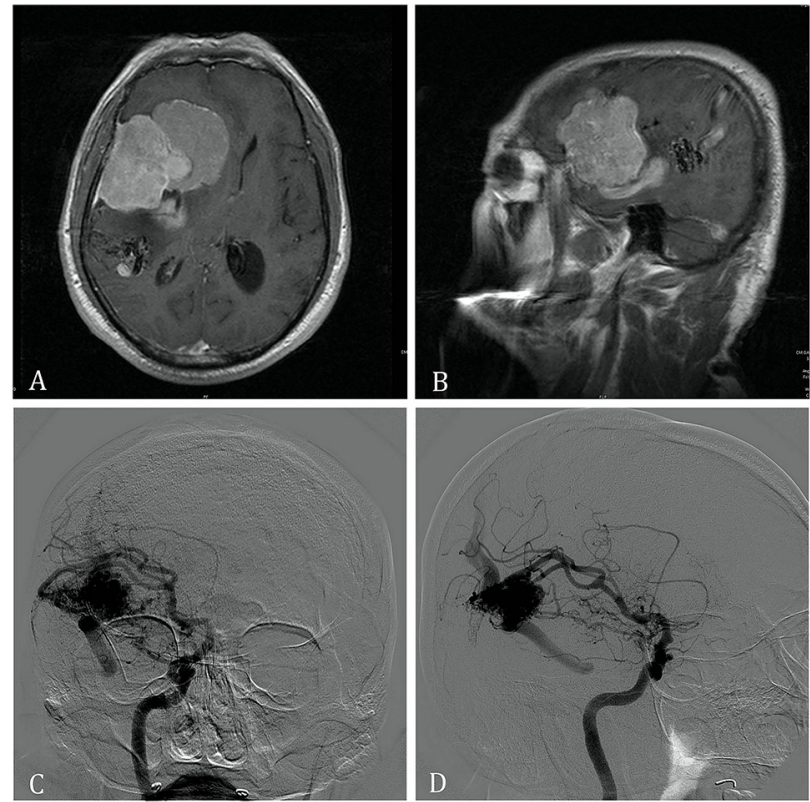

Figure 1. A. Pre-operative Magnetic Resonance, T1-weighted with Contrast, Axial View; B. Pre-operative Magnetic Resonance, T1-weighted with Contrast, Sagittal View; C. Pre-operative Cerebral Angiography, Vascular Lesions such as AVM on the Left Side and; D. Pre-operative Cerebral Angiography, Venous Drainage to Labbè and Trolard Veins are Clearly Demonstrated

\section{Post-operative Course}

After surgery, the patient showed a progressive improvement of the pre-operative symptoms. The post-operative examination displayed a complete removal of the lesions, meningioma and AVM (Figures 2-3). The post-operative imaging discovered a neoplastic lesion of the right pulmonary apex whereby he is now following a specific therapeutic procedures.

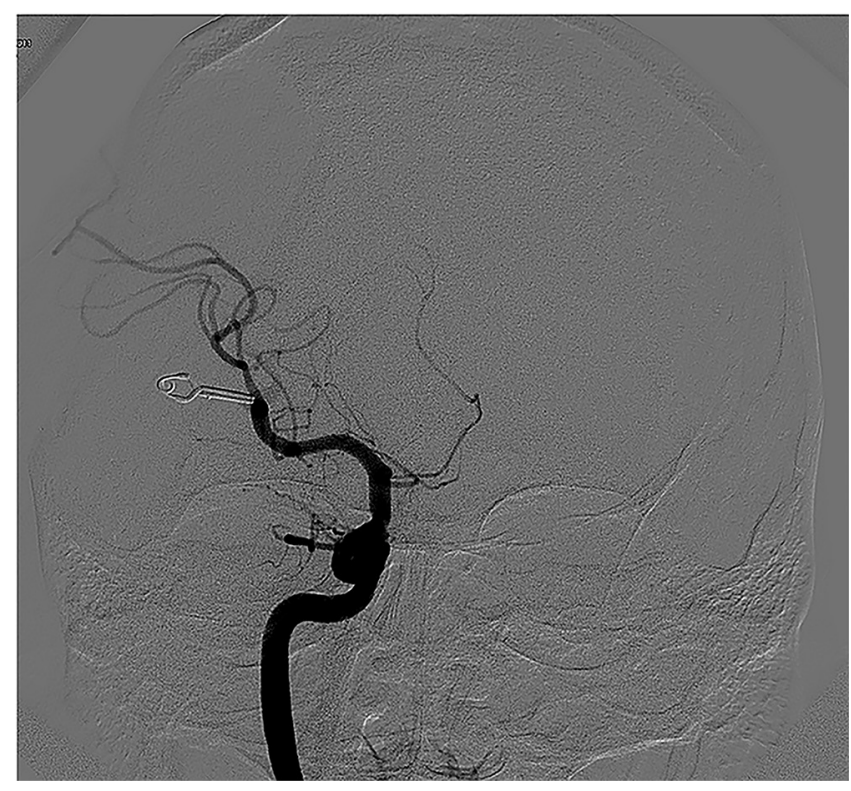

Figure 2. Cerebral Angiography, Coronal View to the Postoperative Scan with the Clipping of the AVM

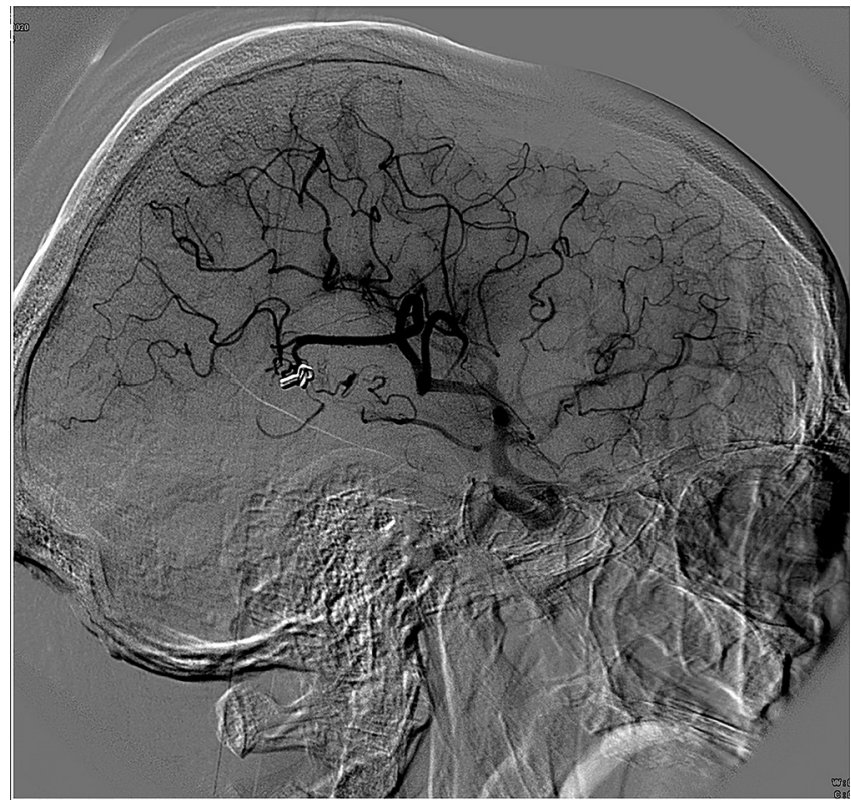

Figure 3. Cerebral Angiography, Sagittal View: the Angiogram Showing the Successfull Resection of the Lesion by the Absence of the Venous Drainage

We reviewed PubMed and Medline publications about the association between meningiomas, AVMs and aneurysms. Therefore, we decided to exclude the association between only two lesions. Our inclusion criteria regarded only patients that presented all three lesions at diagnosis. These publications were analyzed by patient age, site of lesion, and treatment options.

\section{Discussion}

We found only another case, the one described by Fukawa et al. in 1977 (3). However the article is in Japanese (Table 1). Considering the rarity of the case, there is no possibility of a pathophysiology correlation among all these lesions. The contemporary presence of an AVM and aneurism is frequent. The hemodynamic alterations, caused by the arteriovenous shunt, are widely recognized as triggers $(4,5)$. The simultaneous presence of AVM and meningiomas is instead very rare. There are only 14 cases (1) described in literature, excluding our observation. The reason of this association is not clear, although there are some hypotheses. Cushing and Heisenhardt were the first to suggest that chronic flogosis of the arachnoid cells with the typical high-flow rate on arteriovenous shunt of AVMs can be the key factor to facilitate the arising of benign brain tumors (6). Another interesting theory is based on the central pathophysiological role of AVM: Kasanticul et al. speculated that tumor angiogenesis factor (TAF), plus other cytokines released from AVM cells pose a favorable environment for tumor growing (7).

\section{Conclusion}

Our case is the first report in English and the second in the whole literature. However, it is quite hard to find a pathophysiological association among these three lesions. The main reason is the lack of literature on it. There is no doubt about the reason why an AVM and an aneurysm can be found together. The notion neurosurgeons have to be rather focused on is the simultaneous presence of AVM and meningioma. 
Table 1. Comparing Variables in Two Studies

\begin{tabular}{|c|c|c|c|c|c|c|}
\hline Authors & Patient Sex / Age & Symptoms & Site of AVM & $\begin{array}{c}\text { Site of } \\
\text { Meningiomas }\end{array}$ & Site of Aneurism & Type of Treatment \\
\hline $\begin{array}{c}\text { Fukawa et al. } \\
\mathbf{1 9 7 7}\end{array}$ & Man, 56 & $\begin{array}{c}\text { Convulsion of Left } \\
\text { Lower Limb }\end{array}$ & Left Parietal Lobe & Right Parasagittal & $\begin{array}{c}\text { Left Internal Carotid } \\
\text { Surgical Removal for } \\
\text { all Three Cases }\end{array}$ \\
$\begin{array}{c}\text { Boschi et al. } \\
\text { (Present Case) }\end{array}$ & Man; 62 & $\begin{array}{c}\text { Ideomotor Slowing } \\
\text { Down and Tremor of } \\
\text { Right Upper Limb }\end{array}$ & $\begin{array}{c}\text { Deep Right Temporal } \\
\text { Parietal Lobe }\end{array}$ & $\begin{array}{c}\text { Right Frontal } \\
\text { Temporal Convexity }\end{array}$ & $\begin{array}{c}\text { Rise of Ophthalmic } \\
\text { Artery }\end{array}$ & $\begin{array}{c}\text { Retal Surgical } \\
\text { and Menal of AVM } \\
\text { Conservative Therapy } \\
\text { for Aneurysm }\end{array}$ \\
\hline
\end{tabular}

\section{Funding}

None.

\section{Conflicts of Interest}

The authors report no conflicts of interest concerning the materials or methods used in this study or the findings specified in this paper.

\section{References}

1. Moumen N, Arkha Y, Chakir N, Jiddane M. Coexistence of intracranial meningiomas and vascular malformations: A fortuitous association or direct relationship?. Diagnostic and Interventional Imaging. 2012;93(1):67-71.

2. Fischer BR, Palkovic S, Holling M, Niederstadt T, Jeibmann A, Wassmann H. Coexistence of cerebral aneurysm and meningioma-Pure accident?. Clinical Neurology and Neurosurgery. 2009;111(8):647-54.

3. Fukawa O, Tanaka T. [The association of intracranial meningioma with arteriovenous malformation and aneurysm (author's transl)]. No shinkei geka. Neurological Surgery. 1977;5(2):175-80

4. Kader A, Young WL, Pile-Spellman J, Mast H, Sciacca RR, Mohr JP, et al. The influence of hemodynamic and anatomic factors on hemorrhage from cerebral arteriovenous malformations. Neurosurgery. 1994;34(5):801-8.

5. Kondziolka D, Nixon BJ, Lasjaunias P, Tucker WS, TerBrugge K, Spiegel SM. Cerebral arteriovenous malformations with associated arterial aneurysms: hemodynamic and therapeutic considerations. Canadian Journal of Neurological Sciences/Journal Canadien des Sciences Neurologiques. 1988;15(02):130-4.

6. Cushing H, Eisenhardt. Meningiomas: their classification, regional behaviour life history, and surgical end results. Springfield Illinois: Charles C. Thomas; [785] 1938

7. Kasantikul V, Brown WJ. Meningioangiomatosis in the absence of von Recklinghausen's disease. Surgical Neurology. 1981;15(1):71-5.

\section{Comments}

The occurrence of a meningioma in association with a cerebral arteriovenous malformation (AVM) is a recognized but rarely reported finding, less than 20 cases reported in literature. Simultaneously discovered AVM and meningioma with an aneurysm is really rare. Except this case, so far only one report has been found in literature. So from rarity point of view, this case report is very interesting and I should congratulate authors for finding and presenting this documented case. Meanwhile, in Japanese case (the first case of literature) vascular lesions (avm \& aneurysm) were in the left side of the brain and meningioma had grown in the opposite side (right parasagittal region), but in the recent case, Boschi et al. reported all three lesions in the same side of the brain (right hemisphere), this proximity is also noticeable and worth to be thought.

Although there is a few theory for the reason of this association; and the authors have discussed some of the possibilities, but a causal relationship is unproven yet.

Neuro-vacular intervention for treatment of vascular lesions in such a high risk patient (diabetic, hypertensive, presence of COPD and previous myocardial infarction,...), could be an optional treatment either simultaneously with craniotomy as a hybrid operation or separately before the surgical removal of meningioma.

Hamid Etemadrezaie, M.D, Associate Professor of Neurosurgery, Head of Neurosurgical Department of Mashhad University of Medical Sciences, Mashhad, Iran 